\title{
DO DIREITO INTERNACIONAL À GOVERNANÇA GLOBAL: MUDANÇAS ESTRUTURAIS DO ESPAÇO TRANSNACIONAL
}

\section{FROM INTERNATIONAL LAW TO GLOBAL GOVERNANCE: STRUCTURAL CHANGES IN THE TRANSNATIONAL SPACE}

Marcelo Torelly

Doutor em Direito pela Universidade de Brasília, onde atualmente é pesquisador no grupo 'Direito, Sociedade Mundial e Constituição'. Esta pesquisa foi realizada durante meu estágio doutoral junto ao Institute for Global Law and Policy da Faculdade de Direito da Universidade Harvard, Estados Unidos. E-mail: mtorelly@ gmail.com.

Recebido em: 01/06/2016

Aprovado em: 12/08/2016

Doi: $10.5585 / \mathrm{rdb} . v 15 i 6.400$

\begin{abstract}
RESUMO: O artigo examina a emergência do conceito de governança global argumentando que com a complexificação social surgiram novas formas regulatórias transnacionais que desafiam o conceito tradicional de Direito Internacional articulado no início do Século XIX. Propõe uma classificação em três etapas das transformações do espaço transnacional ao longo do Século XX, caracterizadas respectivamente por um período assembleista, outro executivo, chegando ao atual, de judicialização transnacional com ampla fragmentação normativa e o surgimento de regimes auto-continentes com pretensões constitucionais. Metodologicamente, é procedida a descrição das organizações internacionais prevalentes e das teorias jurídicas hegemônicas em cada uma das fases propostas e apresentado um conjunto de características alusivas a cada uma delas. Nas conclusões, são mapeadas sete características distintivas do espaço transnacional ao largo do período analisado: tipo de problema preocupando o campo; estratégias de ação dos operadores; processo de tomada de decisão; estilo de governança; organizações e instituições disponíveis; atores principais; e abordagens teóricas.
\end{abstract}

Palavras-chave: Governança Global. Direito Internacional. Processo Jurídico Transnacional. Fragmentação do Direito Internacional. Governança Transnacional.

\begin{abstract}
The articles analyze the emergence of the concept of global governance arguing that social complexification leads to the emergence of new kinds of transnational regulation that challenge the traditional concept of international law articulated in the late XIX Century. It divides the historical development in three stages: an assembly moment, an executive moment, and judicial moment characterized by normative fragmentation and the emergence of selfcontained regimes with constitutional-like features. Methodologically, it describes the prevailing international organizations and legal theories across time. It concludes mapping seven distinctive features of the transnational space during the three stages: kind of problem concerning the field, strategies of action, decision making process, style of governance, available organizations and institutions, actors, and theoretical approaches.
\end{abstract}

Key-words: Global Governance. International Law. Transnational Legal Process. International Law Fragmentation. Transnational Governance. 
SUMÁRIO: Introdução; 1. Direito Internacional e assembleísmo global; 2. Balanço de poder e capacidade executiva; 3. Fragmentação, regimes jurídicos auto-continentes e novas abordagens constitucionais; 4. Judicialização e processo jurídico transnacional; Conclusões: Evolução e características Estruturais da Governança Global; Referências.

\section{INTRODUÇÃO}

Entendendo "governança" como o modo pelo qual o conjunto de instituições são mobilizadas para a gestão dos assuntos humanos (Kaldor, 2000, p.284), o presente artigo procura mapear as mudanças estruturais tidas ao longo do Século XX que abriram espaço para a emergência do conceito de Governança Global. Argumenta que o conceito de Direito Internacional, pensado no final do Século XIX e início do Século XX em conexão com um conjunto de pressupostos positivistas e idealistas, arquiteta um tipo de governança internacional que, gradualmente, foi sendo ladeado por outras formas regulatórias no espaço transnacional. Essa mudança estrutural do espaço transnacional desafia o conceito clássico de Direito Internacional como direito interestatal, flexibilizando fronteiras entre público e privado, e doméstico e internacional (cf: Koh, 1996).

Para a construção desse argumento, o artigo apropria e atualiza um conjunto de "mapas" sobre a evolução do campo do Direito Internacional produzidos pelo internacionalista norteamericano David Kennedy (especialmente: Kennedy, 2003; 2007), enfatizando sete características-chave dos modelos hegemônicos de governança global que se alteraram radicalmente ao longo do século passado: tipo de problema preocupando o campo; estratégias de ação dos operadores; processo de tomada de decisão; estilo de governança; organizações e instituições disponíveis; atores principais; e abordagens teóricas. A leitura das transformações do Direito Internacional é coordenada pela perspectiva de seu uso como elemento de governança de assuntos de repercussão global. Ou seja, procura enfocar os processos, práticas, leis, tratados, regulamentos, instituições e organizações que, desde a plataforma do Direito Internacional, incidem em processos cuja natureza transcende o "doméstico".

Como forma de estruturar a comparação, argumenta-se pela existência de três momentos distintos no desenvolvimento das formas de governança global ao longo do Século XX. Um primeiro, assembleista, que se estende até a Segunda Grande Guerra, um segundo, de viés tecnocrático-executivo, que se inicia no pós-Guerra e cujas características se mantêm até o final dos anos 1980, atravessando o conflito bipolar, e, finalmente, um terceiro, de judicialização transnacional, que ganha força após o fim da Guerra Fria e dissolução da URSS, cujas características e efeitos se encontram no presente, em processo de aprofundamento. A análise aponta para uma mudança de foco da geração de consensos abrangentes para a resolução de problemas pontuais na ordem internacional, para o fortalecimento de lógicas privadas de resolução de conflitos, especialmente pela via judicial, para um crescente desprestígio da política diplomática como mecanismo decisório e, consequentemente, para a diminuição dos espaço de natureza legislativa na sociedade internacional.

\section{DIREITO INTERNACIONAL E ASSEMBLEÍSMO GLOBAL}

Por muito tempo a literatura historiográfica sobre o Direito Internacional tendeu a apresentar um desenvolvimento relativamente linear para o período compreendido entre a Paz da 
Vestefália e a primeira Grande Guerra ${ }^{1}$. Com o advento da ideia de soberania e sua estabilização política (sopesadas tendências a um uso mais territorial ou mais popular do conceito), construiuse um imaginário de igualdade formal entre os estados, similar àquele outro, doméstico, de igualdade formal entre os cidadãos de um dado Estado. O campo do Direito Internacional emerge como aquele que regula as relações entre Estados. Em consonância, a questão da estatalidade, que tinha uma relevância interna como possibilidade de autodeterminação, ganha relevância externa como possibilidade de participação nas "relações internacionais".

Analisado desde um enfoque de governança, o Século XX será marcado por profundas transformações no Direito Internacional. Uma forma de ilustrar as transformações estruturais do Direito Internacional rumo à governança global pode ser extraída de uma análise das organizações internacionais. De acordo com Kennedy:

Ao longo do Século XX, o foco mudou das instituições plenárias - e de questões de pertencimento [ “membership”], representação ou votação - para administração e, em seguida, resolução de conflitos. A proliferação de órgãos judiciários - incluindo cortes nacionais e corpos arbitrais - que pudemos observar nos últimos vinte anos faz mais sentido quando vista como parte de um movimento mais geral do campo para a desagregação e a juridicização. (Kennedy, 2003, p.403). ${ }^{2}$

Adotando essa classificação tipológica como referência, temos que numa primeira fase de desenvolvimento estrutural do espaço transnacional, cujo marco referencial de término pode ser simbolicamente representado pela Segunda Grande Guerra, o Direito Internacional como projeto foca-se na replicação internacional daquilo que os Estados nacionais construíram domesticamente (processo descrito na literatura como "analogia doméstica"). Assim, os problemas da disciplina serão, primeiramente, se o Direito Internacional é direito ou política, depois, quais suas fontes, e então, finalmente, como organizar tal classe de direito com o "Direito do Estado" de distintos Estados soberanos.

A questão da soberania e a de "ser" um Estado aparece como de primeira grandeza, pois diz respeito diretamente à possibilidade de pertencimento a uma ordem de Estados. A associação entre território, povo e governo, tradicionalmente apresentada como conjunto de requisitos para a obtenção do reconhecimento de estatalidade, traduz para o Direito Internacional o imaginário produzido pelo pensamento e a filosofia modernista durante a constituição dos estados nacionais (Berman, 1992). Se no plano doméstico o recurso a soluções como a ideia de poder constituinte resolve o problema da legitimação interna do Direito, no Direito Internacional tal possibilidade restava interditada (fosse ela pensada faticamente ou hipoteticamente). Portanto, ao buscar

\footnotetext{
${ }^{1}$ Por exemplo, Holsti aponta que "A paz legitimou as ideias de soberania e autonomia dinástica do controle hierárquico. Criou uma moldura de sustentação para a fragmentação política da Europa. O lado oposto da moeda foi deslegitimar todas as formas hegemônicas e os vestígios de controles hierárquicos. [...] A paz construiu algumas das condições indispensáveis para uma ordem internacional razoavelmente estável, particularmente na moldagem de um sistema de governança garantindo o direito de intervenção dos suecos e franceses para defender os termos dos tratados, e pela assimilação dos Habsburgo à ordem, prevenindo potenciais guerras vingativas." Tradução livre, no original: "The peace legitimized the ideas of sovereignty and dynastic autonomy from hierarchical control. It created a framework that would sustain the political fragmentation of Europe. The reverse of the coin was that it delegitimized all forms of hegemony and the vestiges of hierarchical controls. [...] The peace had constructed some of the requisites for a reasonably stable international order, particularly in fashioning a system of governance through the right of Swedish and French intervention to uphold the terms of the treaties, and by assimilating the Hapsburgs into the order, thus pre-empting potential wars of revenge" (HOLSTI, 1991, p.39).

${ }^{2}$ Tradução livre, no original: "Over the twentieth century, the focus has shifted from the plenary institutions - and questions of membership, representation or voting - to administration, and then to dispute resolution. The proliferation of judiciary organs - including national courts and arbitral bodies - that we have seen in the last twenty years makes more sense when seen as part of a more general move in the field to disaggregation and juridification".
}

Revista de Direito Brasileira | São Paulo, SP | v. 15 | n. 6 | p. 20 - 46 | set./dez. 2016 
produzir uma analogia entre direito doméstico e Direito Internacional, o segundo se defrontava com um déficit.

Relendo textos canônicos da doutrina do início do Século XX depreendemos outras consequências da analogia entre a ordem internacional e a doméstica, e o modo como essa forma de pensamento influencia as questões no campo. A ausência de organizações internacionais que pudessem servir a um projeto de governança aparece como um problema central para a aceitação da existência de uma ordem internacional baseada no Direito, e não simplesmente na prática política entre Estados. Em sua obra basilar, Teoria Pura do Direito, dos anos 1930, Kelsen aponta que:

O Direito Internacional, como ordem coercitiva, apresenta o mesmo caráter que o direito nacional, i.e., o direito do estado, mas se distingue dele e apresenta certas similitudes com o direito primitivo, i.e., sociedades sem estado, naquilo em que o Direito Internacional (como direito geral que vincula a todos os estados) não estabelece órgãos especiais para a criação e aplicação de suas normas. Está ainda em um estado de profunda descentralização. Está apenas no início de um desenvolvimento que o direito nacional já completou. (1967, p.323) $)^{3}$.

No contexto de tentativa de construção das primeiras organizações internacionais em sentido hodierno, Kelsen reconhece o Direito Internacional como Direito, apontando sua incompletude. Mas, na ausência de uma instituição que legitime suas normas, como identificálas?

A questão das fontes aparece como uma segunda prioridade neste quadrante histórico. $\mathrm{O}$ problema que se apresenta é que, pensando desde uma perspectiva moderna (no sentido de antinaturalística ou não-tradicional), o Direito Internacional não seria capaz de promover a mesma migração de uma base de legitimação metafísica para outra política, como ocorreu no direito doméstico com a consolidação dos estados nacionais laicos. Os acordos políticos que traduziam a vontade dos atores (aqui os Estados, em substituição aos cidadãos) não podiam ser universalizáveis hipoteticamente por uma ideia totalizante como a de um contrato social mundial. Diferentes Estados possuíam diferentes acordos entre si e o costume, na qualidade de fonte do Direito, colidia com a noção de que a vontade do Estado constitui elemento necessário para a validação de um tratado.

A doutrina das fontes, fortemente vinculada à ideia de estatalidade, passou a construir argumentos para a justificação da existência de fontes consensuais e fontes não consensuais. De acordo com Kennedy:

Por meio do discurso das fontes, doutrinas e argumentos repetidamente invocaram uma distinção entre normas baseadas no consenso e não-baseadas no consenso. A maioria das estratégias retóricas desenvolvidas pelo discurso das fontes pode ser entendida de modo a recapitular, de uma forma ou de outra, essa distinção básica. É utilizada para distinguir tratados de costume, para contrastar várias escolas de pensamento sobre a natureza do costume, para dividir argumentos a favor e contrários à aplicação de normas específicas em várias situações, e de outras dúzias de maneiras ao longo dos materiais alusivos às fontes. (Kennedy, 1987-a, p.88) .

\footnotetext{
${ }^{3}$ Tradução livre, no original: "International law, as a coercive order, shows the same character as national law, i.e., the law of state, but differs from it and shows a certain similarity with the law of primitive, i.e., stateless society in that international law (as a general law that binds all states) does not establish special organs for the creation and application of its norms. It is still in a state of far-reaching decentralization. It is only at the beginning of a development which national law has already completed".

4 Tradução livre, no original: "Throughout sources discourse, doctrines and arguments repeatedly invoke a distinction between consensually and non-consensually based norms. Most of the rhetorical strategies developed by
}

Revista de Direito Brasileira | São Paulo, SP | v. 15 | n. 6 | p. 20 - 46 | set./dez. 2016 
O problema, ainda de acordo com Kennedy, é que "esses dois temas opostos apresentam mais possibilidades retóricas e estratégicas do que identificações decisivas e diferenciações" (ibidem, p.88) ${ }^{5}$. Assim, diferentes decisões judiciais conduzirão a diferentes manejos e reconhecimento de fontes, com distintas teorias justificando ou excluindo determinados conteúdos do escopo do Direito Internacional, mas sempre tendo como referência a existência ou não de uma obrigação interestatal.

Considerando essas preocupações e a centralidade do Estado no horizonte de perspectivas, não é surpreendente que a resposta institucional articulada pelos atores que formulavam o Direito Internacional no período tenha sido a construção de uma instituição "global" de caráter legislativo, a ela vinculando outra de caráter judicial: a Liga das Nações e a Corte Permanente de Justiça Internacional. Não cabe aqui explorar a historiografia sobre a instituição e o fim da Liga, mas sim extrair elementos sobre o estilo de governança proposto pela arquitetura institucional predominante e seu correlato modelo de governança.

Sendo a Liga a primeira organização internacional de caráter amplo, chama a atenção a concentração de poder na Assembleia, e não em unidades executivas, e, especialmente, a necessidade de obtenção de consenso para a tomada de decisões. ${ }^{6} \mathrm{O}$ projeto da Liga, com clara inspiração kantiana, procurava construir as bases institucionais para uma espécie de legislativo mundial onde estados soberanos produziriam o direito e as decisões políticas que os vinculam. Como projeto de governança, a liga prioriza a deliberação política colegiada, e procurava sanear os dois "déficits" comumente associados ao Direito Internacional do período, vez que uma corte passaria a identificar e sistematizar as fontes do Direito, e uma instituição central, de caráter colegiado, faria as vezes de agente de deliberação e implementação.

A segunda classe de preocupações atinentes ao estilo de governança proposto pelo Direito Internacional anterior à Segunda Grande Guerra diz respeito à sua relação com o direito doméstico. Se efetivamente o Direito Internacional é Direito, e em existindo instituições relativamente análogas nos âmbitos doméstico e internacional, como proceder em caso de conflito entre as ordens jurídicas?

Para além de identificar as fontes do Direito Internacional, surgia a necessidade de coordenar hierarquicamente suas normas com aquelas do direito doméstico. Em texto de 1936, J.G. Starke sumariza o problema nos seguintes termos: "são o Direito Internacional e o direito doméstico aspectos de uma mesma realidade jurídica (monismo), ou são eles realidades normativas distintas (dualismo)? Qual sistema normativo prevalece na hierarquia jurídica, Direito Internacional ou direito doméstico?" $(1936, \mathrm{p} .67)^{7}$.

O problema da unidade do Direito que preocupava o pensamento tradicional desde a antiguidade clássica, passando pelo medievo, volta a emergir não mais no bojo do pensamento naturalista, mas como questão de não contradição racional. Não mais como uma questão de relacionamento entre lei humana e lei divina, mas de relacionamento entre sistemas formais de comandos normativos que, eventualmente, entram em conflito lógico-operativo. De um lado,

sources discourse can be understood to recapitulate in one form or another this basic distinction. It is used to distinguish treaties from custom, to contrast various schools of thought about the nature of custom, to divide arguments for and against the application of specific norms in various situations, and in dozens of other ways throughout the materials on sources".

5 Tradução livre, no original: "these two opposed themes present rhetorical possibilities and strategies more than decisive identifications and differentiations".

${ }^{6}$ Covenant of the League of Nations, $28^{\text {th }}$ April 1919, article 05(01): "Except where otherwise expressly provided in this Covenant or by the terms of the present Treaty, decisions at any meeting of the Assembly or of the Council shall require the agreement of all the Members of the League represented at the meeting. "

7 Tradução livre, no original: "Are international law and municipal law concomitant aspects of the same juridical reality (monism), or are they quite distinct normative realities (dualism)? Which normative system stands higher in the legal hierarchy, international law or municipal law?".

Revista de Direito Brasileira | São Paulo, SP | v. 15 | n. 6 | p. 20 - 46 | set./dez. 2016 
uma resposta dualista tenderia a uma contradição performática, vez que algo poderia, a um só tempo, ser direito e não-direito, impedindo a realização do ideal de perfeição do Direito.

De outro lado, uma resposta monista, pela mesma razão, impõe a necessidade de alguma forma de solução hierárquica para o conflito, preservando a coerência, mas desdobrando a questão em outra, sobre precedência normativa. O binômio interno/externo garante a coesão tanto das ordens jurídicas domésticas quanto do Direito Internacional, mas o problema da necessidade de hierarquização entre as ordens para a construção de soluções de unidade formal cresce proporcionalmente com o desenvolvimento das instituições e de sua capacidade normativa.

O fracasso da Liga das Nações como modelo não afastou esta questão embora, por razões pragmáticas, na nova arquitetura decisória construída no período seguinte ela tenha perdido parte de sua relevância empírica.

\section{BALANÇO DE PODER E CAPACIDADE EXECUTIVA}

Se a ideia da Liga das Nações era, centralmente, promover a paz através de um modelo de governança e organização política internacional, seguramente a Segunda Grande Guerra se apresenta como sintoma do fracasso prático da proposta. Não obstante, após a Guerra, com o estabelecimento da Organização das Nações Unidas (ONU), o projeto hegemônico de governança global seguiu sendo aquele da construção de uma instituição abrangente. O ideário predominante ainda era o de que "a institucionalização da vida internacional se parece com a própria essência da paz” (Kennedy, 1987-b, p.859) ${ }^{8}$.

A grande diferença desta segunda fase é a rotação de foco da política legislativa para ação executiva (que posteriormente permitiu a insurgência de novas agências, setoriais e técnicas, com capacidade de gestão focal). Tal rotação é um desdobramento da cumulação de um conjunto de fatores estruturais associados ao novo modelo de governança representado pela ONU. Em termos concretos, a nova arquitetura institucional pensada na estruturação das Nações Unidas refletia uma maior preocupação com o balanço de poder do que com a representação proporcional. Novos mecanismos como o poder de veto e o deslocamento do centro de poder da Assembleia Geral para o Conselho de Segurança igualmente refletem esse afastamento de uma perspectiva parlamentarista rumo a um modelo de gestão executiva, estruturado sobre as bases de um sistema de limitações recíprocas focado não na integralidade dos Estados-membros, mas em um conjunto de atores estratégicos e relevantes.

Esse formato de gestão orientou, igualmente, a estruturação de distintas agências e organizações especializadas. A crítica ao modelo de organização política da Liga das Nações, e das dificuldades decorrentes de seu processo deliberativo colegiado, orientaram uma nova lógica em que, para além da instituição internacional central, organizações periféricas receberam ampla delegação para a gestão de problemas específicos. Os exemplos mais candentes são a criação do Fundo Monetário Internacional (FMI) e do Banco Mundial, durante as conferências em Bretton Woods, em 1944; a Organização Mundial da Saúde, em 1948; e a Agência Internacional de Energia Atômica, em 1957.

A abordagem positivista e a preocupação com a codificação e as fontes do Direito Internacional são substituídas por uma abordagem funcionalista, mais preocupada com a administração e o gerenciamento de políticas do que com processos deliberativos. Consequentemente, a Assembleia Geral, esvaziada politicamente e ideologicamente demarcada pelo conflito bipolar entre Leste e Oeste, perde espaço para agendas setoriais específicas de estruturação multilateral de acordos e convenções sobre direitos.

A agenda de incidência do Direito Internacional também muda após a Segunda Grande Guerra. Se antes a preocupação era o gerenciamento colonial, depois a descolonização é o tema

${ }^{8}$ Tradução livre, no original: "the institutionalization of international life can seem the very essence of peace". Revista de Direito Brasileira | São Paulo, SP | v. 15 | n. 6 | p. 20 - 46 | set./dez. 2016 
premente. Se nacionalismo e autodeterminação tencionavam a agenda geopolítica, agora a construção de novos Estados torna-se central (Sassen, 2003, p.16), e o problema do desenvolvimento ganha mais evidência (Kennedy, 2003, p.402).

Ainda, a consolidação das sociedades industriais nos países centrais e a divisão do mundo entre liberais e comunistas alimenta agendas regionais próprias, com diferentes traduções de debates políticos em catálogos de direitos. Os Estados Unidos enfatizavam a liberdade e o mercado. O Bloco Soviético avançava uma agenda internacional pró-igualdade, bloqueando iniciativas pró-liberdades individuais. Enquanto isso, a Europa caminhava no sentido de consolidar um modelo de Estado Social. Projetos sociais distintos que reconhecem direitos e lhes dão extensão de maneiras radicalmente divergentes.

Um exemplo de estilo de abordagem do Direito Internacional nesta segunda fase pode ser obtido na leitura do artigo "Positivism, Functionalism, and International Law" de Hans Morgenthau (1940), que adianta em grande medida o que viria a ser um dos modelos predominantes de entendimento do Direito Internacional como mecanismo de governança da sociedade mundial: o funcionalismo. Nessa linha de pensamento o Direito é central para a governança, mas a conceituação de seus princípios regentes em grande medida desdiferencia o Direito da Política e da força. Morgenthau aponta que:

Os preceitos do Direito Internacional devem não apenas ser interpretados à luz dos ideais e princípios ético-jurídicos que conformam sua base. Eles também precisam ser vistos no contexto sociológico dos interesses econômicos, das tensões sociais, e das aspirações de poder, que estão motivando as forças no campo internacional, e que dão origem às situações fáticas que compõem a matéria prima da regulação pelo Direito Internacional. (1940, p.269) ${ }^{9}$.

Ao contrário da pretensão positivista de construção de uma ordem universal neutra, as abordagens predominantes durante o conflito bipolar tendem ao uso do Direito Internacional como mecanismo de construção de uma ordem global ideologicamente orientada. Novamente exemplificando com Morgenthau:

Por um lado, o Direito Internacional é a função da civilização na qual ele se origina, ou seja, das ideias reguladoras assentadas na ética e nos costumes ["mores”] dessa civilização, das forças sociais políticas, econômicas e gerais vigentes na mesma, e, finalmente, dos fatores psicológicos específicos que se manifestam nos indivíduos que o determinam. Por outro lado, o Direito Internacional é um mecanismo operando em direção a determinados fins nessa mesma civilização que, por sua vez, tanto quanto determinada por ele, se torna uma função desse mesmo Direito Internacional. Ao sistematizar as regras de um dado Direito Internacional sob o ponto de vista desta relação funcional dual entre regras e forças sociais, a teoria funcionalista chegará a um entendimento realmente científico da matéria elementar das regras jurídicas que o positivismo, mesmo em seu melhor, foi capaz apenas de descrever e sistematizar de acordo com pontos de vistas legalistas superficiais. (ibidem, p.274) ${ }^{10}$.

\footnotetext{
${ }^{9}$ Tradução livre, no original: "The precepts of international law need not only to be interpreted in the light of the ideals and ethico-legal principles which are at their basis. They need also to be seen within the sociological context of economic interests, social tensions, and aspirations for power, which are the motivating forces in the international field, and which give rise to the factual situations forming the raw material for regulation by international law".

${ }^{10}$ Tradução livre, no original: "On the one hand, international law is the function of the civilization in which it originates, that is, of the regulative ideas laid down in the ethics and mores of this civilization, of the political, economic and general social forces prevailing in it, and, finally, of the specific psychological factors manifesting themselves in the individuals determining it. On the other hand, international law is a social mechanism working towards certain ends within this same civilization which, in turn, as far as determined by it, becomes a function of this same international law. By systematizing the rules of a given international law under the viewpoint of this dual

Revista de Direito Brasileira | São Paulo, SP | v. 15 | n. 6 | p. 20 - 46 | set./dez. 2016
} 
A consequência dessa abordagem é um modelo completamente diverso do que seja o Direito Internacional. Primeiro, o Direito Internacional é explicitamente identificado com um balanço de poder corrente nas relações internacionais, e não com um balanço de forças estático do momento da aprovação de um determinado instrumento legal. Na abordagem funcionalista, de cariz realista, o Direito Internacional deriva sua utilidade de um consenso em uma comunidade de interesses ou de uma necessidade ante a um balanço de poder. Assim, se um determinado interesse deixa de existir, apenas o equilíbrio de poder e a ameaça ao recurso à força mantém o Direito.

Segundo, a validade é conectada com a capacidade efetiva de sanção:

Uma regra de Direito Internacional não recebe sua validade de sua promulgação em um instrumento legal, como, por exemplo, um tratado internacional, como o positivismo estava disposto a acreditar. Há regras de Direito Internacional que são válidas, embora não promulgadas em um instrumento legal desta natureza, e há regras de Direito Internacional que não são válidas, embora promulgadas em tais instrumentos. A promulgação, portanto, não é um critério objetivo para a alegada validade de uma regra de Direito Internacional. Uma regra, seja ela jurídica, moral, ou convencional, é válida quando sua violação é suscetível de ser seguida por uma reação desfavorável, ou seja, uma sanção contrária ao violador. Uma alegada regra, cuja violação não seja seguida por tal sanção, é uma simples ideia, um desejo, uma sugestão, mas não uma regra válida (ibidem, p.276) ${ }^{11}$.

O modelo de governança de estruturas como o Conselho de Segurança da ONU claramente incorpora essa perspectiva. $O$ texto e a interpretação legal constituem apenas uma parte do processo de deliberação da tomada de decisões efetivas, e não está sujeito à revisão judicial por nenhum outro órgão. A contrariedade a um interesse implica em uma limitação ao Direito. A dimensão da validade formal empalidece ante a uma hipertrofia realista quanto a facticidade da norma.

Terceiro, o Direito Internacional pode ser dividido em duas classes. Na primeira estão as normas que traduzem interesses permanentes (ou constantes) dos Estados e, consequentemente, são mais estáveis. Na segunda, encontram-se as normas que decorrem de interesses momentâneos, flutuantes ou conjunturais. O direito costumeiro, por exemplo, é do primeiro tipo. Ele não deriva sua vigência da prática reiterada, mas sim o oposto, a prática reiterada ilustra sua vigência.

Quarto, múltiplas fontes garantem validade ao Direito Internacional. Não apenas as fontes clássicas do texto legal e precedentes jurídicos que preocupavam os positivistas, mas também leis morais, éticas e a vontade política. Quanto mais entrelaçadas as relações, maior a chance de que um dado interesse seja protegido e, conforme, "Direito". Novamente, a distinção entre facticidade e validade é turvada, e a ordem internacional e seu direito ilustram uma indistinção entre Direito e Política na sociedade mundial.

functional relationship between rules and social forces, the functional theory will arrive at a real scientific understanding of the material element of the legal rules which positivism even at its best was able to describe and systematize only according to superficial legalistic viewpoints".

${ }^{11}$ Tradução livre, no original: "A rule of international law does not, as positivism was prone to believe, receive its validity from its enactment into a legal instrument, as, for instance, an international treaty. There are rules of international law which are valid, although not enacted in such legal instruments, and there are rules of international law which are not valid, although enacted in such instruments. Enactment, therefore, is no objective criterion for the alleged validity of a rule of international law. A rule, be it legal, moral, or conventional, is valid when its violation is likely to be followed by an unfavorable reaction, that is, a sanction against its violator. An alleged rule, the violation of which is not followed by such a sanction, is a mere idea, a wish, a suggestion, but not a valid rule". 
Quinto, o modelo de interpretação típico da Civil Law mostra-se inadequado, vez que as forças sociais nas relações internacionais são extremamente dinâmicas e capazes de incidir no Direito.

Finalmente, sexto, a abordagem funcionalista critica o positivismo que lhe precedeu como abordagem dominante por sua desconexão com os processos efetivos de governança e tomada de decisão:

A ciência do Direito Internacional, completamente absorta em problemas práticos quanto a quais devam ser as regras do Direito Internacional, tem prestado praticamente nenhuma atenção para as leis psicológicas e sociológicas que governam as ações dos homens na esfera internacional, ou para as possíveis regras jurídicas que se desenvolvem a partir de tais ações. (ibidem, p.283) ${ }^{12}$.

Evidentemente o pensamento de Morgenthau, por mais influente que tenha sido, não resume toda a enorme pluralidade de entendimentos sobre o Direito Internacional em um largo período histórico. Porém, ele é suficiente para exemplificar - até mesmo pelo extremo de certas posições - algumas tendências. A primeira, já mencionada, é o deslocamento do foco das instituições que produzem e aplicam o Direito Internacional de um eixo deliberativo e parlamentar, em que uma ideia de igualdade se faz presente, para um eixo executivo, no qual a tomada de decisão dentro de um contexto de equilíbrio de forças é necessária.

Uma segunda, consequente com a primeira, é uma mudança de foco de atenção "do Direito" para "o problema jurídico". Todo o debate sobre fontes diz respeito a buscar o que é ou onde está o Direito. Numa abordagem funcionalista o processo de tomada de decisão ganha relevância. Não é o Direito quem resolve o problema, mas sim o processo, e neste processo é que se encontra aquilo que o Direito realmente é. As fontes, os precedentes, os tratados e a doutrina são parte de um processo de tomada de decisão, e a combinação entre decisão tomada e capacidade de implementação (por persuasão ou força), é que efetivamente determina o que o Direito é.

Uma terceira, a ideia de uma instituição abrangente perde força. A complexidade social e a variedade dos problemas a serem enfrentados pelo Direito Internacional é por demais extensa para ser abrangida por uma instituição totalizante. O pluralismo normativo e a multiplicação de agências decisórias não são um acidente de percurso, mas sim uma consequência de um projeto de governança global que foca não no todo, mas em problemas específicos. Agências especializadas, a um só tempo, contaminam-se menos com conflitos originados em outras agências (o que não seria possível em uma única instituição abrangente) e, ainda, consolidam um vernáculo e uma racionalidade compartilhada entre agentes, facilitando o gerenciamento de conflitos. Em um contexto de balanço de poder radicalizado, uma estrutura descentralizada e especializada é mais gerenciável do que uma estrutura central, tanto por envolver menos atores, quanto por legitimar um discurso técnico que, teoricamente, não é capturado pela lógica preponderante da disputa política.

Outras experiências igualmente ilustram o gradual abandono da perspectiva presente no Direito Internacional do início do Século XX de se equiparar ao direito doméstico por meio da construção de um "estado global”. O melhor deles muito provavelmente é a União Europeia. Sem pretender-se um superestado que governa por sobre os Estados, a União funciona como mecanismo de governança supranacional. Apesar de possuir uma estrutura parlamentar, o modelo de governança da União Europeia em grande medida acompanha a tendência de concentração de

\footnotetext{
${ }^{12}$ Tradução livre, no original: "The science of international law, completely absorbed by practical problems as to what the rules of international law should be, is paying almost no attention to the psychological and sociological laws governing the actions of men in the international sphere, nor to the possible legal rules growing out of such actions".
} 
poder decisório nas agências executivas, o que leva autores como Kennedy a apontar que "o processo decisório na União Europeia deslocou competências legislativas dos parlamentos para o executivo e moveu a autoridade das regiões para o centro, fragmentando o Estado" (1994, p.22) ${ }^{13}$.

O exemplo da União Europeia é interessante pois permite verificar o alinhamento de três níveis de governo (doméstico, supranacional e internacional) em um mesmo projeto. $\mathrm{O}$ direito doméstico gradualmente desloca sua capacidade decisória e, consequentemente, possibilidades de enunciação e efetivação de direitos, para agências especializadas do Executivo, cujos atos podem ser revisados pelo Judiciário. Isso inverte o modelo tradicional de organização política nos estados nacionais, no qual os parlamentos deliberam e fiscalizam e a administração executa.

No plano internacional percebe-se o deslocamento de um modelo deliberativo orientado pela formação de consensos políticos para um modelo de gestão, orientado pela solução de problemas em agências especializadas, em que um balanço de forças dinâmico equilibra interesses divergentes. A União Europeia surge com um exemplo que explicita a conexão entre estes dois processos: a um só tempo ilustra a transferência de capacidade decisória dos parlamentos democráticos para unidades técnico-executivas especializadas que respondem pouco a mecanismos democráticos, e a verticalização de processos decisórios antes tidos de maneira soberana no estado nacional para unidades supra ou transnacionais, menos responsivas ao contexto político territorial local.

\section{FRAGMENTAÇÃO, REGIMES JURÍDICOS AUTO-CONTINENTES E NOVAS ABORDAGENS CONSTITUCIONAIS}

No final do Século XX, em um aparente paradoxo, o fim do conflito bipolar não produziu um reengajamento no ideário do Estado mundial. No início do Século o projeto cosmopolita encontrava abrigo entre alguns Estados liberais. No final do Século, o ideário neoliberal radicaliza a crítica à existência e funções do Estado, de tal maneira que o paradigma emergente do fim do conflito bipolar propugna uma globalização sem Estado, onde forças econômicas e sociais se autorregulam. De acordo com Martii Koskenniemi e Päivi Leino, "a estrutura proporcionada pelo confronto Leste-Oeste foi substituída por uma realidade caleidoscópica na qual atores concorrentes lutam para criar sistemas normativos concorrentes, muitas vezes expressamente para escapar das restrições do direito diplomático" $\left(2002\right.$, p.559) ${ }^{14}$.

O relatório de 2006 da Comissão de Direito Internacional das Nações Unidas sobre o tema "fragmentação do Direito Internacional" contextualiza o fenômeno da emergência de novos regimes jurídicos como um problema de especialização funcional de setores da sociedade mundial:

Uma das características da modernidade internacional tardia tem sido o que os sociólogos definem como 'diferenciação funcional', a crescente especialização de partes da sociedade e sua correlata autonomização. Isso toma lugar tanto nacional quanto internacionalmente. É um paradoxo bastante conhecido da globalização que, ao mesmo tempo em que produziu uma crescente uniformização da vida social ao redor do mundo, também gerou uma crescente fragmentação - ou seja, gerou a emergência de esferas e estruturas de ação

\footnotetext{
${ }^{13}$ Tradução livre, no original: "the EU decision-making process has shifted legislative competence from parliaments to the executive as it has moved authority from the regions to the center, fragmenting the state".

14 Tradução livre, no original: "the structure provided by the East-West confrontation was replaced by a kaleidoscopic reality in which competing actors struggled to create competing normative systems often expressly to escape from the strictures of diplomatic law".
} 
social especializadas e relativamente autónomas. (United Nations, 2006, item $08)^{15}$.

O fenômeno de diferenciação e especialização funcional da sociedade mundial, ainda segundo a Comissão de Direito Internacional, "alcançou especial relevância jurídica por ter sido acompanhado da emergência de regras, complexos de regras, instituições jurídicas, e esferas de prática jurídica especializadas e (relativamente) autônomas"(ibidem) ${ }^{16}$. A ideia presente é que a fragmentação social conduz a uma especialização funcional de setores do direito que, descolando-se de um Direito Internacional "geral", passam a produzir instituições e expedir normativas próprias para a regulação de suas atividades e campos. Tal processo se inicia no Direito Internacional Público, no qual surge a ideia de "regimes auto-continentes", mas depois expande-se para regimes privados.

De acordo com Bruno Simma e Dirk Pulkowski (2006, p.491), a primeira utilização jurisprudencial da ideia de regime auto-continente ocorre ainda em 1923, quando a Corte Permanente de Justiça Internacional, no caso SS Wimbledon ${ }^{17}$, entende que provisões específicas do Tratado de Versalhes devem ser compreendidas como "auto-continentes", criando um regime próprio que se diferencia do Direito Internacional Geral. Os desenvolvimentos posteriores do Direito Internacional apenas estimularam e ampliaram o processo de especialização, na medida em que novas agências executivas foram estabelecidas e passaram a promover regulação com base em conhecimento especializado.

Ainda, a maior interação entre atores não estatais ensejou a construção de complexos mecanismos de governança privada, cujas regras próprias não necessariamente dialogam com aquelas dos sistemas públicos de governança, exceto em casos de conflito, quando podem vir a ser adjudicadas, ou de necessidade de coordenação, como no exemplo do Direito Administrativo Global (cf.: Kingsbury, Krisch e Stewart, 2005).

De acordo com o relatório da Comissão de Direito Internacional:

O que antes parecia ser governado pelo "Direito Internacional geral" se tornou o campo de operação de sistemas especializados tais quais "direito comercial", "direito dos direitos humanos", "direito ambiental", "direito do mar", "direito europeu", e mesmo alguns tão exóticos e de conhecimento altamente especializado como "direito do investimento" ou "Direito Internacional dos refugiados" etc. - cada um possuindo seus próprios princípios e instituições. (United Nations, 2006, item 08) ${ }^{18}$.

Se no início do Século XX havia premente preocupação em constituir organizações mínimas capazes de produzir governança, aqui já se percebe uma situação oposta: a proliferação de organizações cria problemas de superposição de autoridade jurídica e política. A esse processo

\footnotetext{
${ }^{15}$ Tradução livre, no original: "One of the features of late international modernity has been what sociologists have called "functional differentiation", the increasing specialization of parts of society and the related autonomization of those parts. This takes place nationally as well as internationally. It is a well-known paradox of globalization that while it has led to increasing uniformization of social life around the world, it has also lead to its increasing fragmentation - that is, to the emergence of specialized and relatively autonomous spheres of social action and structure". UNITED NATIONS. International Law Commission. Fragmentation of International Law: difficulties arrising from the diversification and expansion of International Law. (A/CN.4/L.682), Genebra, 2006, item 07.

16 Tradução livre, no original: "has attained legal significance especially as it has been accompanied by the emergence of specialized and (relatively) autonomous rules or rule-complexes, legal institutions and spheres of legal practice".

${ }^{17}$ Permanent Court of International Justice (P.C.I.J.) The case of the S.S. Wimbledon. P.C.I.J 1923 (ser. A) No. 1.

${ }^{18}$ Tradução livre, no original: "What once appeared to be governed by "general international law" has become the field of operation for such specialist systems as "trade law", "human rights law", "environmental law", "law of the sea", "European law" and even such exotic and highly specialized knowledges as "investment law" or "international refugee law" etc. - each possessing their own principles and institutions".
}

Revista de Direito Brasileira | São Paulo, SP | v. 15 | n. 6 | p. 20 - 46 | set./dez. 2016 
de expansão pluralista de regimes legais independentes ou parcialmente independentes do Direito Internacional geral, somam-se os efeitos do declínio da estatalidade, compreendida como a transferência de poder público para atores não-estatais e o exercício de autoridade pública por meios, igualmente, não-estatais (Grimm, 2005, p.447). Novamente, conforme Koskenniemi e Leino:

A crise da soberania doméstica é paralela ao colapso da imagem do mundo internacional como uma estrutura hierárquica unitária que tem a Organização das Nações Unidas em seu topo, governando um mundo de soberanias domesticadas por meio do direito público e da diplomacia. A nova configuração global se constrói sobre relacionamentos informais entre diferentes tipos de unidades e atores, uma vez que o papel do Estado se transformou de legislador em facilitador de sistemas autorregulados. A economia é, obviamente, global. Mas "internacional" e "nacional" podem não ser mais separáveis de maneira útil mesmo como domínios distintos na política e governo. $\left(2002\right.$, p.557) ${ }^{19}$.

A soma entre os processos de globalização, declínio da estatalidade e, consequentemente, de redimensionamento da constituição doméstica e a emergência de racionalidades e formas privadas de governança, leva autores como Gunther Teubner (2012) a enxergar nos novos regimes especializados e auto-continentes "fragmentos constitucionais" de um direito mundial, compondo aquilo que ele define como um "constitucionalismo societal" cuja lógica se aproxima a de uma soberania de coletivos de autogoverno proposta por Ulrich Preuss (2010). De acordo com Teubner:

[...] regimes auto-continentes se fortalecem como regimes auto-constitucionais. A característica definidora dos regimes auto-continentes não é simplesmente que eles criam regras primárias altamente especializadas, i.e. regras substantivas em campos especiais do direito, mas sim que eles também produzem suas próprias normas processuais de produção legislativa, reconhecimento de regras, e sanção jurídica: as chamadas regras secundárias. $\left(2010\right.$, p.333) ${ }^{20}$.

Desde esta perspectiva, no final do Século XX, a consolidação da especialização funcional de regimes jurídicos reduz, em parte, a desdiferenciação entre Direito e Política percebida nas décadas anteriores, vez que a atividade de regulação se concentra na consolidação entre partes de regras setoriais com maior coesão. Assumindo como fato a especialização funcional, essa abordagem propõe que o Estado nacional não é a única fonte normativa em uma sociedade mundial, e que o problema da colisão entre regimes jurídicos, sejam eles públicos ou privados, transcende a dissonância normativa formal - nos termos apresentados em boa parte do relatório da Comissão de Direito Internacional, por exemplo - referindo-se diretamente a um choque entre racionalidades sistêmicas conflitantes.

Teubner exemplifica esses conflitos com um caso de colisão de racionalidades entre o direito derivado dos direitos fundamentais e direito derivado da economia transnacional:

\footnotetext{
${ }^{19}$ Tradução livre, no original: "The crisis of domestic sovereignty is paralleled by the collapse of the image of the international world as a single, hierarchical structure at the top of which the United Nations governs a world of tamed sovereigns through public law and diplomacy. The new global configuration builds on informal relationships between different types of units and actors while the role of the state has been transformed from legislator to a facilitator of self-regulating systems. The economy is, of course, global. But the "international" and "national" may no longer be usefully separated even as distinct realms of politics and government".

${ }^{20}$ Tradução livre, no original: "[...] self-contained regimes fortify themselves as auto-constitutional regimes. The defining feature of self-contained regimes is not simple that they create highly specialized primary rules, $i e$ substantive rules in special fields of law, but that they also produce their own procedural norms on law-making, law recognition, and legal sanction: so-called secondary rules".
} 
Nessa perspectiva, presumidas violações contra os direitos humanos praticadas por empresas transnacionais não são apenas conflitos entre direitos individuais entre o direito de propriedade das firmas e os direitos humanos das pessoas. Mais que isso, elas representam a colisão entre racionalidades institucionalizadas. Elas são incorporadas em diferentes políticas de organizações transnacionais. Tais problemas são causados pela fragmentação e pelos sistemas funcionais operativamente fechados da sociedade mundial que, em seu fervor expansionista, criam os problemas mais urgentes da sociedade global. $(2010, \text { p.330 })^{21}$.

Independente da aceitação da ideia de que os regimes transnacionais sejam fragmentos de um direito constitucional societal, o ponto nevrálgico do debate sobre pluralismo e a fragmentação do Direito Internacional é a percepção de que os regimes especializados constituem um dado novo e relevante. A solução de conflitos entre diferentes regimes passa a depender menos da formulação de propostas hierarquizantes entre diferentes formas normativas e mais da estruturação de mecanismos e processos de influência recíproca entre atores estratégicos dos diferentes regimes.

Nesse contexto as cortes e órgãos análogos, na qualidade de espaços capazes de conectar racionalidades e produzir decisões vinculantes em algum dos regimes ou ordens jurídicas implicados no problema legal em apreço, ganham especial relevância, podendo funcionar como espaços institucionais que possibilitam comunicações entre regimes que, de outra maneira, seguem operando em uma lógica fechada. O espaço judicial é aquele que melhor reflete a busca por neutralidade que orienta a lógica privada de resolução de conflitos que caracteriza o período pós-bipolarismo. Menos que buscar acordos relevantes e a construção de consensos sobre a existência e distribuição de direitos, o projeto de governança global passa a se focar em solucionar disputas entre partes específicas, com capacidade para litigar, consequentemente pressionando o eixo de produção do Direito, deslocando-o de um espaço mais participativo e universalizável para outro, de acesso mais restrito, especializado e técnico.

\section{JUDICIALIZAÇÃO E PROCESSO JURÍDICO TRANSNACIONAL}

Em sua terceira fase de alterações estruturais, a governança global incorpora muito da perspectiva técnica e fragmentária comumente identificada com o Direito, de um lado, constituindo um modelo de governança jurídica tecnocrática e, de outro, produzindo alterações no modus operandi do próprio Direito, adequando-o ao novo projeto de governança. O Direito é entendido (e promovido) como tecnologia social de solução setorial de conflitos a um só tempo neutra e imparcial, capaz, portanto, de promover maior racionalidade e eficiência na regulação de temas globais. Sem perder a dimensão funcional da abordagem da fase anterior, o discurso predominante do Direito Internacional absorve os novos valores de governança neoliberal. Apresenta-se como mediador institucional capaz de garantir a efetivação da neutralidade e eficiência, valores priorizados pelo discurso do "mercado", fortalecido pela expansão das novas formas de regulação na esfera privada (Sassen, 2006, p.192).

Para que possa se manter neutro, o Direito precisa ser mantido afastado da Política, razão pela qual as cortes passam a ganhar espaço como produtoras jurídicas ante aos corpos

\footnotetext{
${ }^{21}$ Tradução livre, no original: "In this light, the alleged violations of human rights by transnational enterprises are not only conflicts between individual rights - between the property Rights of the firms and the human rights of the people. Rather, they represent the collisions of institutionalized rationalities. They are embodied in the different policies of transnational organizations. Such problems are caused by the fragmented and operationally closed functional systems of a global society, which, in their expansionist fervour, create the most pressing problems of global society".
} 
legislativos. Igualmente, numa lógica individualista, decisões judiciais se mostram mais eficientes para aqueles que podem litigar do que as políticas públicas produzidas pela governança de estilo legislativo ou executivo, que demandam tempo para produção de consensos e, somente depois, resultados.

Se no início do Século, na primeira fase de desenvolvimento, a principal matriz de geração normativa do Direito Internacional era, mesmo que idealmente, o processo deliberativo, servindo a Liga das Nações como exemplo, a gradual autonomização de instituições e agências executivas capazes de produzir autorregulação durante a segunda fase substitui a racionalidade deliberativa pela ideia de racionalidade da expertise. Justificativas que partem de uma certa leitura da concepção burocrático-weberiana para explicar o afastamento da Política em prol de uma maior eficiência técnica constituem um dos pilares estruturais do modus operandi da segunda e da terceira fase (cf.: Esty, 2006, p.1517). Outro pilar é, justamente, a ideia de neutralidade. Se as instituições e agências executivas são compostas acomodando interesses assimétricos de Estados e atores privados, é necessário um Direito capaz de mediar conflitos de forma neutra, proporcionando equilíbrio "técnico-jurídico" à equação de poder.

Essa perspectiva fica bem expressa na reconstrução histórica e, consequentemente, nas implicações normativas que Harold Koh extrai em sua leitura sobre as transformações na ordem mundial do pós-Guerra. Ele inicia contextualizando o sonho de sobrepor o Direito ao poder, cuja concretização seria brecada pela Guerra Fria:

Os anos que imediatamente se seguiram à Segunda Guerra Mundial representam o auge do Direito Internacional: o surgimento das Nações Unidas e de organizações internacionais, tanto políticas quanto econômicas, o movimento internacional por direitos humanos, e a noção de que os internacionalistas poderiam ser simultaneamente os arquitetos e os executores de uma nova ordem mundial fundada no direito. Primordialmente, aqueles que desenharam o sistema internacional do pós-Guerra eram advogados que acreditavam no império do direito, não na força, no trato dos assuntos internacionais, e na boa vontade dos Estados em cooperar no âmbito das instituições internacionais e constitucionais. $\left(\right.$ Koh, 1996, p.191) ${ }^{22}$.

Situando-se em um ponto de equilíbrio entre o positivismo característico do início do Século e o realismo brutal do período da Guerra Fria, leituras do Direito Internacional presentes em autores como Harold Koh ou Anne-Marie Slaughter (2003) reaproximam perspectivas divorciadas entre Direito Internacional e direito doméstico. Aqui o Direito não se apresenta como ultima ratio capaz de regular estados soberanos, mas tão pouco como simples expressão dos interesses, permanentes ou tópicos, dos mesmos.

Se para autores como Morgenthau uma norma não efetiva simplesmente deixa de ser parte do Direito, para os internacionalistas do final do Século o próprio conceito de "observância" ["compliance”] do Direito Internacional flexibiliza-se, na medida em que a aplicação do Direito não resta adstrita a uma perspectiva "tudo ou nada". Utilizando uma analogia de Koh como ilustração:

Somente porque o limite de velocidade de 55 milhas por hora não é rigorosamente observado não decorre que o direito carece absolutamente de

\footnotetext{
22 Tradução livre, no original: "The years immediately following World War II represented the heyday of international law: the rise of the United Nations and international organizations, both political and economic, the international human rights movement, and the notion that international lawyers could be both the architects and executors of a new world order under law. In the main, those who designed the postwar international system were lawyers who believed in the rule of law, not power, in international affairs and in the willingness of states to cooperate within international institutional and constitutional frameworks".
} 
força . Quando o limite de velocidade é 55, as pessoas tendem a dirigir a 65, e não a 85. O Direito pode estar sub-aplicado, pode estar aplicado de maneira imperfeita, mas é ainda assim aplicado, não meramente por um processo legislativo doméstico, por uma decisão judicial, ou pela ação do executivo, mas por um processo de aplicação que transparece em uma variedade de foros públicos e privados, em uma variedade de leis domésticas e internacionais, desencadeado por uma variedade de atores governamentais e não governamentais. $(1996, \text { p.194) })^{23}$.

A gradual emergência de regimes especializados com seus próprios regramentos, processos de autorregulação domésticos, e a maior interação entre tribunais locais, nacionais, supranacionais, transnacionais e internacionais, ampliam o debate sobre observância, uma vez que "para além de ser formalmente implementado em regras jurídicas domésticas, o Direito Internacional pode afetar a interpretação do direito doméstico" (Howse \& Teitel, 2010, p.132) ${ }^{24}$. As perspectivas hierárquicas características do início do Século são substituídas por abordagens sobre conflito e cooperação entre ordens e regimes jurídicos que enfrentam questões jurídicas superpostas, e o campo do Direito Internacional passa a sobrevalorizar o equacionamento de interesses pela localização e sopesamento de princípios, e não apenas pela implementação de regras.

A dimensão judicial da governança ganha um espaço sem precedente, ampliando o espaço para litígios de natureza transnacional ou, quando pouco, cujo impacto terá consequências que não se limitam ao plano doméstico ou ao internacional no sentido dualista, atravessando diferentes ordens e regimes jurídicos. Segundo Slaughter, litígios transnacionais, diferentemente de resolução de disputas internacionais, "geralmente referem litígios em tribunais domésticos, tipicamente entre partes privadas através das fronteiras, mas também, na medida em que as imunidades soberanas se enfraquecem, entre partes privadas e Estados" $(2003, \text { p.191 })^{25}$.

Com a maior integração global a quantidade e variedade de conflitos a serem mediados por cortes e órgãos análogos também se incrementa. Ainda, a quantidade de direito "setorial" (fragmentado) disponível igualmente resta ampliada: regimes especializados, tratados bilaterais ou multilaterais, acordos privados entre outros. Distintos processos conduzem a produção de ampla regulação aplicável em caso de conflito, e os regimes ainda se observam e se referem reciprocamente, ampliando a complexidade do processo de acomodação de expectativas em torno do processo jurídico que se desenvolve em um ou vários deles (cf.: Neves, 2009).

Daí decorre que o próprio direito a ser aplicado na solução de um litígio pode tornar-se objeto de conflito. Assim, gradualmente, o papel mediador das cortes ganha relevo. Não porque a produção de tipo "legislativo" do Direito Internacional deixe de existir, em que pese a pluralização das fontes, nem porque as agências executivas deixem de produzir políticas públicas, em que pese a emergência de projetos privados com características de políticas públicas, mas simplesmente porque a soma desses dois processos e a fragmentação das instituições de governança produz conflitos que demandam soluções "neutras" e "eficientes" caracteristicamente associadas com aquelas produzidas por cortes de justiça.

\footnotetext{
${ }^{23}$ Tradução livre, no original: "Just because the $55 \mathrm{mph}$ speed limit is not strictly enforced does not mean that that law lacks all power. When the speed limit is 55 , people tend to drive 65 , not 85 . The law may be underenforced, it may be imperfectly enforced, but it is enforced, not by a simple domestic process of legislation, adjudication, and executive action, but by a process of complex enforcement that transpires in a variety of public and private fora, under a variety of domestic and international laws, triggered by a variety of governmental and nongovernmental actors".

${ }^{24}$ Tradução livre, no original: "beyond being formally implemented in domestic legal rules, international law may affect the interpretation of domestic law".

${ }^{25}$ Tradução livre, no original: "generally referred to litigation in domestic courts, typically between private parties across borders but also, as sovereign immunity rules loosened, between private parties and states".
}

Revista de Direito Brasileira | São Paulo, SP | v. 15 | n. 6 | p. 20 - 46 | set./dez. 2016 
As perspectivas hierarquizantes do início do Século XX procuraram responder tais conflitos hierarquicamente, questionando qual norma de qual ordem ou regime deveria ter precedência, implicando conflito entre regimes (doméstico vs. internacional; geral vs. especializado). As abordagens funcionalistas, por sua vez, focaram no equilíbrio de interesses e na capacidade efetiva de implementação factual das normas. $\mathrm{Na}$ abordagem da atual fase de desenvolvimento estrutural da governança global, a reconstrução da ideia de neutralidade do Direito somada à persistência da perspectiva funcionalista de resolução de problemas permite uma construção alternativa.

Operando num espaço que Slaughter define como uma "comunidade global de cortes", os juízes percebem-se como envolvidos em um "empreendimento judicial comum" em que enfrentam "problemas institucionais e substantivos compartilhados; aprendem com as experiências e raciocínio uns dos outros; e cooperam diretamente para resolver disputas específicas. Crescentemente, eles se concebem como capazes de atuar de maneira independente tanto no domínio internacional, quanto no doméstico" (Slaughter, 2003, p.193) ${ }^{26}$. Evidentemente um empreendimento conjunto só é possível onde existem valores compartilhados, e a crença no Direito como ferramenta neutra de equacionamento de conflitos é um destes valores.

Como consequência do aumento do uso e da maior capacidade decisória das cortes, e da insurgência do discurso da expertise, as cortes internacionais, transnacionais e espaços jurídicos de decisão gradualmente são empoderados. No processo de resolução de conflitos, as cortes e órgãos análogos definem o que é e o que não é Direito, revisam decisões administrativas e políticas públicas, enumeram e restringem direitos. Se na primeira fase de desenvolvimento os Estados detinham o monopólio sobre a produção do Direito, e o esforço de coordenação era empreendido por meio de acordos políticos, na segunda fase organizações internacionais e transnacionais, públicas e privadas, igualmente tornaram-se atores relevantes em um contexto em que definições substantivas ocorrem no bojo de agências executivas.

A terceira fase, cujas operações coexistem com as da segunda, mas que avança na consolidação de uma lógica privada de governança, caracteriza-se pela incorporação no processo de produção do Direito Internacional de todo ator (individual ou coletivo, público ou privado) com capacidade de litigar, e o foco deixa de ser a construção de acordos para ser a solução de conflitos. Partes "individuais" passam a figurar em um debate cujo senso de unidade e organização era antes dado apenas por entes coletivos soberanos: os Estados. Pessoas naturais ou jurídicas são inseridas como contrapartes privadas em um sistema de governança que antes era eminentemente público, forçando uma reorganização de estruturas de legitimação, categoriais analíticas, e dos próprios conceitos de pertencimento, unidade e organização do sistema de governança ainda em curso e cujos resultados não são de antemão previsíveis ${ }^{27}$. A combinação entre capacidades existentes, racionalidades em disputa, e alterações estruturais implica em rearranjos profundos que, quando analisados desde uma perspectiva global, mostram-se setoriais, plurais ou mesmo fragmentários.

Novamente citando Slaughter, o Direito Internacional amplia seu escopo estabelecendo um "foco liberal não nas interações entre os Estados, ao menos não em primeira instância, mas sim em um conjunto analítico de relações entre estados e a sociedade civil doméstica e transnacional" (1993, p.207) ${ }^{28}$. Nesta perspectiva, a diferenciação entre direito e política no plano global conduz a uma desdiferenciação entre o doméstico e o internacional:

\footnotetext{
26 Tradução livre, no original: “common substantive and institutional problems; [...] learn from one another's experience and reasoning; and [...] cooperate directly to resolve specific disputes. Increasingly, they conceive of themselves as capable of independent action in both international and domestic realms".

${ }^{27}$ Nesse sentido, por exemplo, veja-se: Torelly, 2015.

${ }^{28}$ Tradução livre, no original: "liberal focus not on state-to-state interactions, at least not in the first instance, but on an analytically prior set of relationships among states and domestic and transnational civil society".
}

Revista de Direito Brasileira | São Paulo, SP | v. 15 | n. 6 | p. 20 - 46 | set./dez. 2016 
A mudança conceitual a ser destaca é a de dois sistemas - internacional e doméstico - para um; de juízes internacionais e nacionais para juízes aplicando o Direito Internacional, o direito nacional, ou uma mistura entre ambos. Em outras palavras, a identidade institucional de todas essas cortes, e a identidade profissional dos juízes que nelas tem assento, é forjada mais por sua função comum de resolver disputas por meio de regras de direito do que pelas diferenças no direito que eles aplicam e as partes que pleiteiam em frente a eles. (Slaughter, 2003, p.192) ${ }^{29}$.

O deslocamento de parte relevante do processo deliberativo substantivo para cortes, por sua vez, implica uma alteração do estilo de governança, que se torna mais judicial e, consequentemente, ainda mais tecnocrático. Juízes treinados em alguma especialidade jurídica passam a definir o Direito aplicando, com critérios relativamente fluídos, o Direito Internacional, o direito doméstico, ou uma mistura entre ambos. Ainda, o processo de litígio ganha espaço frente as formas de produção tradicional do Direito, como a deliberação político-legislativa. $\mathrm{O}$ "processo jurídico transnacional" torna-se, a um só tempo, mecanismo de produção e implementação do Direito. De acordo com Harold Koh:

Processo jurídico transnacional descreve a teoria e a prática sobre como atores públicos e privados - estados nacionais, organizações internacionais, empresas multinacionais, organizações não governamentais, indivíduos privados interagem em uma variedade de maneiras públicas e privadas, em foros domésticos e internacionais, para criar, interpretar, aplicar e, finalmente, internalizar regras de direito transnacional. (1996, pp.183-184) ${ }^{30}$.

Koh apresenta o processo jurídico transnacional como uma resposta para diversos dos problemas oriundos da reorganização do sistema jurídico ante ao declínio da estatalidade e a emergência de uma ordem global plural e fragmentada. Primeiro, o processo jurídico transnacional não é nem doméstico nem internacional, nem público nem privado. Tribunais domésticos, supranacionais ou internacionais participam do processo sem hierarquias préestabelecidas. Órgãos privados de resolução de conflitos também se fazem presentes. Qualquer ator capaz de litigar pode dar início a uma causa. Formas de direito "geral", doméstico ou internacional, convivem com regimes especializados.

Segundo, o processo é não estatal. Isso significa mais que albergar a possibilidade de incorporar atores privados, pois implica igualmente a possibilidade de excluir atores públicos. Exemplos como tribunais arbitrais independentes, a International Organization for Standardization (ISO), ou a Federação Internacional de Futebol Associado (FIFA), ilustram formas organizacionais em que processos com resultados determinantes de direitos ou produtores de regulação ocorrem em grande medida à margem de qualquer regulação estatal.

Terceiro, o processo jurídico transnacional é dinâmico: "o direito transnacional se transforma, muda, e filtra para cima e para baixo, subindo do doméstico ao internacional e de

\footnotetext{
${ }^{29}$ Tradução livre, no original: "The underlining conceptual shift is from two systems -international and domestic- to one; from international and national judges to judges applying international law, national law, or a mixture of both. In other words, the institutional identity of all these courts, and the professional identity of the judges who sit on them, is forged more by their common function of resolving disputes under rules of law than by the differences in the law they apply and the parties before them".

30 Tradução livre, no original: "Transnational legal process describes the theory and practice of how public and private actors - nation-states, international organizations, multinational enterprises, non-governmental organizations, and private individuals - interact in a variety of public and private, domestic and international fora to make, interpret, enforce, and ultimately, internalize rules of transnational law".
} 
volta para baixo" (Koh, 1996, p.184) ${ }^{31}$. O direito tradicional, doméstico ou internacional, é estático. Depende de processos organizacionais complexos, sua alteração é lenta, suas interações mediadas. O direito transnacional, conforme pensado por Koh, é ágil, pois orientado para a resolução de problemas, e não a si mesmo.

Finalmente, quarto, é normativo. Normas são estabelecidas, validadas e derrogadas nos processos de composição e litígio transnacional. Numa mediação entre a validade formal conforme pensada pelos positivistas, e o Direito como efetividade da abordagem funcionalista, Koh propõe um conceito de normatividade baseado na ideia de influência das normas, tomando como fato a necessidade que todos os atores, inclusive os Estados, têm de interagir no cenário global:

Resumindo, a ideia crítica é a normatividade do processo jurídico transnacional. Para sobreviver em um mundo interdependente, mesmo os Estados mais isolados - Coréia do Norte, Líbia, Iraque, Cuba - precisam eventualmente interagir uns com os outros. Mesmo estados párias não conseguem isolar-se eternamente do cumprimento do Direito Internacional se desejam participar em uma economia ou em processos políticos transnacionais. Uma vez que as nações começam a interagir, um processo complexo ocorre, por onde normas jurídicas internacionais se infiltram, são internalizadas, e acabam incorporadas nos processos legais e político em âmbito doméstico. (ibidem, p.205) ${ }^{32}$.

Ainda, ao permitir novas formas de interação, e ao abrir possibilidades de participação para atores não estatais, viabiliza novas formas de legitimação do processo decisório, em interações livres da preponderância da lógica de governança estatal. Nas palavras de Teitel, isso viabiliza que as cortes articulem e deem efetividade a um discurso sobre "direitos", em oposição a um discurso político que prevalece, inclusive, no Conselho de Segurança da Organização das Nações Unidas (orientado por uma lógica de balanço de poder):

A judicialização muda o poder, de um lado, permitindo a responsabilização jurídica, de outro, empoderando atores não estatais que, por sua vez, dirigindo-se de variadas maneiras às cortes e tribunais internacionais e em sendo abordados por eles, se transformam em agentes legitimadores. Cortes e tribunais internacionais estão bem posicionados para prover um discurso baseado em direitos autônomos ou, ao menos, parcialmente descolado da cultura política e do constitucionalismo nacional - universalizável, secular, transnacional, e com a autoridade dos mais elevados valores humanos. (Teitel, 2014, p.111) ${ }^{33}$.

O processo jurídico transnacional, como teoria explicativa da normatividade e da legitimação de decisões, procura dar conta das novas realidades regulatórias para além do Estado

\footnotetext{
${ }^{31}$ Tradução livre, no original: "transnational law transforms, mutates, and percolates up and down, from the public to the private, from the domestic to the international level and back down again".

32 Tradução livre, no original: "To summarize, the critical idea is the normativity of transnational legal process. To survive in an interdependent world, even the most isolated states - North Korea, Libya, Iraq, Cuba - must eventually interact with other nations. Even rogue states cannot insulate themselves forever from complying with international law if they wish to participate in a transnational economic or political process. Once nations begin to interact, a complex process occurs, whereby international legal norms seep into, are internalized, and become embedded in domestic legal and political processes".

${ }^{33}$ Tradução livre, no original: "Judicialization shifts power on the one hand by promoting judicial accountability, and on the other by empowering nonstate actors, who, in turn, by addressing themselves in various ways to international courts and tribunals and by being addressed by them, become agents of legitimacy. International courts and tribunals are well situated to supply a rights-based discourse at least partly detached or autonomous from national political cultures and constitutionalism - universalizable, secular, transnational, and with the authority of high human values".
}

Revista de Direito Brasileira | São Paulo, SP | v. 15 | n. 6 | p. 20 - 46 | set./dez. 2016 
nacional. Ele incorpora processos como a arbitragem e a negociação ao acervo tradicional de produção do Direito. Ao fazê-lo, abre-se a novos atores. Valendo-se dos exemplos de Koh:

[...] o Direito Internacional é aplicado em processos jurídicos transnacionais desencadeados não apenas pelos Estados Unidos ou a Rússia, mas também pelo Conselho de Segurança, GATT, Exxon, Greenpeace, o Clube de Paris, a Anistia Internacional, e o escritório Lowenstein de Direito Internacional dos Direitos Humanos da Escola de Direito da Yale. (Koh, 1996, p.194) ${ }^{34}$.

Da perspectiva internacional, esse processo conduz à ampliação do campo do Direito, conforme apontado por Slaughter mas, sobremaneira, a uma ampliação do papel daquelas instituições dotadas de capacidade de decisão: as cortes. Da perspectiva do direito doméstico, implica um desafio à identidade constitucional ou, como prefere Grimm, um certo "rebaixamento constitucional": "na medida em que o Estado se compromete na mesa de negociações, os processos constitucionais e as autoridades legitimadas para a tomada de decisões segundo a constituição são rebaixados" (Grimm, 2005, p.455) $)^{35}$.

Em outros casos, mesmo sem se comprometer, os Estados passam a ter seu espaço de ação constrito por outros atores estratégicos. Gradualmente, mesmo os direitos fundamentais, fortemente vinculados às constituições nacionais, passam a ser enumerados ou ter seu escopo redefinido por processos jurídicos transnacionais movidos por atores que não figuram no "elenco" tradicional do direito constitucional (Cf: Torelly, 2015; Torelly, 2016-B). Nessa perspectiva, os atores privados com capacidade de produzir alterações substanciais na regulação jurídica podem ser, grosso modo, divididos em dois grupos: com ou sem fins lucrativos (cf.: Pattberg, 2005).

O primeiro grupo é de mais fácil identificação: atores econômicos, como corporações "que, em razão do alcance de suas atividades, podem em grande medida seguir sua própria lógica sistêmica sem necessariamente respeitar os padrões e obrigações que prevalecem dentro dos Estados" " (Grimm, 2005, p.457) ${ }^{36}$. O segundo grupo, de atores privados sem fins lucrativos, inclui todo o heterogêneo segmento conhecido como "sociedade civill". O número de organizações não governamentais reconhecidas por organizações internacionais de Direito Público ampliou-se dramaticamente durante o Século XX. De acordo com Sassen (2006, p.151), enquanto em 1914 havia registro de pouco mais de 330 organizações deste tipo, no ano de 1980 esse número ultrapassava 6.000 .

Esses novos atores, privados, entram em litígio e se mobilizam politicamente dentro de regimes especializados que operam "em uma disputa hegemônica na qual cada um pretender ter seus interesses especiais identificados com o interesse geral" (Koskenniemi \& Leino, 2002, p.562) ${ }^{37}$. As relações se estabelecem dentro de uma lógica prevalentemente privada, de litígio individual ante a um agente que promoverá uma decisão neutra, de defesa de interesses setoriais, e expansão da racionalidade de um regime para outros. Não obstante, o interesse em jogo dentro do regime pode ser público ou privado.

Exemplos como o da autorregulação de empresas atuantes em um dado mercado explicitam um jogo entre interesses predominantemente privados. Casos de litígio de direitos

\footnotetext{
${ }^{34}$ Tradução livre, no original: “[...] international law is enforced by a transnational legal process, which is triggered not just by the United States and Russia, but also by the Security Council, the GATT, Exxon, Greenpeace, the Paris Club, Amnesty International, and the Lowenstein International Human Rights Clinic at Yale Law School".

${ }^{35}$ Tradução livre, no original: "to the extent that the state commits itself at the negotiating table, the constitutionally prescribed decision-making authorities and procedures are downgraded".

${ }^{36}$ Tradução livre, no original: "which, by virtue of the range of their activities, can largely follow their own systemic logic without having to respect the standards and obligations that prevail within states".

${ }^{37}$ Tradução livre, grifos dos autores, no original: "in a hegemonic struggle in which each hopes to have its special interests identified with the general interest".
}

Revista de Direito Brasileira | São Paulo, SP | v. 15 | n. 6 | p. 20 - 46 | set./dez. 2016 
humanos em cortes internacionais explicitam o uso de uma lógica privada, qual seja, a adjudicação individual, mas podem ter em vista um interesse público (cf.: Cardoso, 2012). Assim, a mudança de estilo do Direito Internacional rumo a um modelo mais judicial não implica na eliminação dos valores e interesses associados com as esferas pública e privada, mas produz um rearranjo relevante na maneira como direitos são enumerados e efetivados e, mais ainda, nos modos de mobilização para produção de mudanças jurídicas e políticas.

\section{CONCLUSÕES: EVOLUÇÃO E CARACTERÍSTICAS ESTRUTURAIS DA GOVERNANÇA GLOBAL}

Quais, então, as principais características que podem ser identificadas no processo de mudança estrutural do espaço transnacional do Direito Internacional rumo à governança global? Sete categorias analisadas ao longo deste texto estão sistematizadas no Quadro 01, e permitem a distinção entre as três diferentes fases de desenvolvimento e, consequentemente, para a estruturação da resposta a essa questão.

Quadro 01: Características Estruturais do Direito Internacional no Século XX

\begin{tabular}{|c|c|c|c|}
\hline & $1^{\mathrm{a}}$ Fase & $2^{\mathrm{a}}$ Fase & $3^{a}$ Fase \\
\hline Época & $\ldots-1950$ & $1950-1980$ & $1980-\ldots$ \\
\hline Tipo de Problema & $\begin{array}{l}\text { Fontes do Direito } \\
\text { Internacional }\end{array}$ & $\begin{array}{l}\text { Políticas Públicas } \\
\text { Internacionais }\end{array}$ & $\begin{array}{l}\text { Princípios Legais e } \\
\text { Boas Práticas }\end{array}$ \\
\hline $\begin{array}{ll}\text { Estratégia } & \text { de } \\
\text { Abordagem } & \end{array}$ & Codificação & $\begin{array}{l}\text { Administração } \\
\text { (gerenciamento) }\end{array}$ & $\begin{array}{l}\text { Litígio e Resolução } \\
\text { de Conflitos }\end{array}$ \\
\hline $\begin{array}{l}\text { Processo de } \\
\text { Tomada de Decisão }\end{array}$ & Deliberação Plenária & $\begin{array}{l}\text { Executiva } \\
\text { (Tecnocrática) }\end{array}$ & $\begin{array}{l}\text { Judicial } \\
\text { (Tecnocrática) }\end{array}$ \\
\hline $\begin{array}{ll}\text { Estilo } & \text { de } \\
\text { Governança } & \end{array}$ & Legislativo & Executivo & Judiciário \\
\hline $\begin{array}{l}\text { Organizações } \\
\text { Governo }\end{array}$ & $\begin{array}{l}\text { Estados } \\
\text { Organizações } \\
\text { Internacionais }\end{array}$ & $\begin{array}{l}\text { Estados; } \\
\text { Organizações, } \\
\text { Instituições } \\
\text { Agências } \\
\text { Internacionais e } \\
\text { Supranacionais; } \\
\text { Organizações Não- } \\
\text { Governamentais }\end{array}$ & $\begin{array}{l}\text { Estados; } \\
\text { Organizações, } \\
\text { Instituições } \\
\text { Agências } \\
\text { Internacionais } \\
\text { Supranacionais; } \\
\text { Organizações Não- } \\
\text { Governamentais; } \\
\text { Regimes Privados }\end{array}$ \\
\hline Atores & $\begin{array}{l}\qquad \text { Estados } \\
\text { Organizações } \\
\text { Internacionais }\end{array}$ & \begin{tabular}{l}
\multicolumn{1}{c}{ Estados, } \\
Organizações \\
Internacionais \\
Regimes
\end{tabular} & \begin{tabular}{l}
\multicolumn{1}{c}{ Estados, } \\
Organizações \\
Internacionais, \\
Regimes, \\
Corporações, ONG's \\
e Indivíduos
\end{tabular} \\
\hline $\begin{array}{l}\text { Abordagen } \\
\text { s Teóricas }\end{array}$ & $\begin{array}{l}\text { Positivismo } \\
\text {, engenharia social, } \\
\text { estatalidade }\end{array}$ & $\begin{array}{l}\text { Balanço de } \\
\text { Poder, realismo } \\
\text { funcionalista, } \\
\text { construção da } \\
\text { Ordem Global }\end{array}$ & $\begin{array}{l}r \text { Pragmatism } \\
\text { o, legitimação } \\
\text { expertise, } \\
\text { humanista }\end{array}$ \\
\hline
\end{tabular}

Fonte: sistematizado pelo autor especialmente a partir de: Kennedy, 2007, pp.651, 653; 2003, pp. 400, 402, 403, 406-7. 


\section{a) Tipo de problema}

É possível identificar uma mudança no tipo de problema no qual o Direito Internacional, como disciplina, concentrou-se ao largo de seu processo de mudança estrutural. Na primeira fase de desenvolvimento, o campo seguiu debruçado sobre os problemas típicos do pensamento jurídico do Século XIX, procurando compor uma teoria abrangente sobre as fontes do Direito Internacional, resolvendo questões como a compatibilização entre o direito resultante do acordo entre os estados e o direito consuetudinário. Na segunda fase, o foco migra para a política pública internacional. A preocupação normativa abre lugar para a tentativa de execução coordenada de projetos regulatórios, com a priorização de atores estratégicos, o desenvolvimento de tecnologias específicas, e a incorporação de agências transnacionais e atores privados relevantes no processo decisório. Finalmente, na terceira fase, de amplo pluralismo legal, vocaciona o campo para a busca de princípios legais aplicáveis e padrões de políticas desejáveis, inclusive com a introdução de uma nova gramática de governança que inclui ideias como a de "boas práticas", e a consolidação de políticas globais públicas, privadas e público-privadas.

A produção e positivação de regras, cuja forma era extremamente relevante, é abertamente substituída por uma perspectiva funcional baseada mais na capacidade de persuasão do que em ideais normativos de validade. Problemas relacionados às fontes não desaparecem, mas deixam de ser uma questão central. Novos direitos passarão a surgir no espaço transnacional não como produto de novos acordos políticos, mas como interpretações de instrumentos préexistentes por agências decisórias de natureza técnica. Nesse sentido, a estratégia de ação para a obtenção de direitos não necessariamente passa por sua "codificação", mas por sua busca na observação recíproca.

\section{b) Estratégias de ação}

A resposta aos problemas acima referidos é articulada por meio de uma estratégica de ação, que também é atualizada na medida em que o campo se transforma. A preocupação com as fontes implica em uma estratégia de codificação. A produção de legislação internacional, de fontes positivas, é uma preocupação-chave para aqueles que propõem formas de governança por meio do Direito Internacional durante toda a primeira e, ainda, parte da segunda fase de desenvolvimento aqui estruturadas. Os Estados são os principais protagonistas desse empreendimento coletivo, e a diplomacia o meio por excelência para a obtenção dos fins almejados.

Durante a segunda fase, gradualmente, o foco em gerenciamento de políticas em um contexto de ausência de consenso implica a migração de uma estratégia de codificação para outra, de administração. A impossibilidade de obter um consenso razoável sobre um determinado tema não pode significar seu bloqueio na agenda internacional, e a falência do modelo da Liga das Nações é, entre outros, atribuída a seu complexo processo deliberativo. A necessidade premente de dar respostas rápidas e efetivas fortalece as abordagens de tipo problem solving em detrimento daquelas focadas tanto em aplicar quanto em produzir normativas generalizáveis. O foco global é substituído pelo enfoque tópico.

Finalmente, na terceira fase, com a consolidação de um cenário de pluralismo legal e com a ampliação radical dos atores habilitados a participar da ordem internacional, o enfoque tópico é individualizado. O litígio e a resolução de disputas tornam-se as principais estratégias para a produção e efetivação do Direito Internacional. O aumento das relações privadas bilaterais e multilaterais de modo não necessariamente dependente do Estado igualmente amplia a quantidade de conflitos. $\mathrm{O}$ fortalecimento de lógicas privadas de governança, que veem o Estado com desconfiança, estimula tanto a criação de espaços não-estatais de litígio e resolução de 
conflitos, quanto o privilegiamento de cortes e tribunais, associados com a prática "independente" (neutra) do direito em contraposição à política.

A mobilização política por mudanças legais e enunciação de direitos também responde a essa alteração estrutural do modelo de governança. Organizações não governamentais de interesse público (atores privados) e movimentos sociais institucionalizados ou não passam a identificar no litígio uma forma estratégica de promoção de uma agenda política de expansão de direitos. Tal processo desloca parte da agenda de mobilização da construção de consensos amplos sobre a legitimidade de certas demandas, que então se traduzem em direitos, para a utilização de casos individuais emblemáticos para a construção de novas interpretações do Direito. Parte significativa da mobilização social é transferida da luta política por positivação de direitos para estratégias jurídicas de demonstração e persuasão quanto à adequação social de uma determinada leitura jurídica, mixando atuação política e técnica na construção (e reconstrução) de direitos.

\section{c) Tomada de decisão}

A mudança de tipo de problema e estratégia de abordagem altera o processo de tomada de decisões radicalmente. $\mathrm{O}$ exemplo da Liga das Nações ilustra a construção de uma arquitetura orientada à realização institucional de uma lógica deliberativa parlamentar expressando uma preocupação em tornar a governança internacional análoga àquela doméstica, com uma clara ênfase em um modelo de prevalência do corpo Legislativo sobre os órgãos executivos e judiciais. A preocupação democrática traduz o conceito de cidadania individual doméstica em outro, de soberania estatal, de tal maneira que todos os Estados soberanos possam ser tratados com igualdade na ordem internacional.

O modelo das Nações Unidas e dos regimes especializados, por sua vez, afasta a lógica parlamentar dando ênfase às agências executivas, concentrando poder de fato em um órgão em que a igualdade entre Estados soberanos é preterida ante um modelo de balanço de poder explícito. O Conselho de Segurança exemplifica uma nova racionalidade, na qual os processos decisórios relevantes são deslocados para a esfera de controle e influência de atores centrais, ao mesmo tempo em que os demais envolvidos podem operar em uma lógica cooperativa periférica.

Mais ainda, enquanto na primeira parte da segunda fase podemos observar a articulação de regimes especializados, num segundo momento eles claramente assumem um papel-chave nos processos deliberativos e decisórios em âmbito global. Os exemplos do Banco Mundial e do Fundo Monetário Internacional são explícitos quanto a este novo modelo. Agências com baixa representação democrática são legitimadas por sua expertise para a "boa governança" e passam a exercer autoridade pública desde uma racionalidade privada fulcrada na objetividade técnica e em pressupostos de eficiência.

A terceira fase consolida as cortes e órgãos análogos como espaços centrais para a solução de conflitos em uma sociedade mundial em que organizações econômicas tornam-se substancialmente independentes dos Estados nacionais, e na qual uma pluralidade de atores, públicos e privados, domésticos, transnacionais, supranacionais e internacionais, além de indivíduos singulares, legitimam-se a participar dos processos de governança dos quais são sujeitos. A lógica de solução interindividual de conflitos substitui em grande medida a anterior, de composição de interesses geoestratégicos.

A atividade judicial é ampliada radicalmente. Na esfera pública, com a criação de inúmeros tribunais internacionais para a solução de problemas de natureza pública ou privada, em temas cujo arco se expande do direito penal ao direito comercial. Na esfera privada, com a constituição de mecanismos de arbitragem e solução de conflitos que substituem a justiça administrada por autoridades legitimadas de forma direta ou indireta pelo direito público doméstico ou internacional. A expansão da esfera privada e o declínio da estatalidade implicam uma gradual e crescente redistribuição de capacidades decisórias de governo em um fluxo cujo 
vetor se desloca do doméstico para o internacional e o transnacional, e do público para o privado. Há uma reconcentração de capacidade de governo em novos atores, privados e transnacionais.

\section{d) Estilo de governança}

Assim, se no início do Século XX o estilo de governança do Direito Internacional era predominantemente legislativo, com questões formais quanto ao pertencimento e participação na ordem internacional ocupando local privilegiado na reflexão acadêmica, a segunda fase de desenvolvimento estrutural passa a trabalhar em um estilo executivo. Os fins tornam-se mais relevantes que os meios, e a abordagem de estilo realista-funcionalista, como a de Morgenthau, turvam a separação entre Direito e poder. O estilo judicial da terceira fase retoma as preocupações com uma diferenciação mais clara entre facticidade e validade do Direito, porém, a concepção do que o Direito é e como ele se estrutura é radicalmente diferente, como exemplificado pela abordagem do constitucionalismo societal de Gunther Teubner.

A mudança de estilo de governança, mais do que apenas refletir as alterações no tipo de problema, estratégia de abordagem e formato de tomada de decisão, acompanha a tendência mais ampla verificada na sociedade mundial de tecnicização, desnacionalização e privatização. A ideia de que processos majoritários de tomada de decisão são morosos e, muitas vezes, irracionais, é compartilhada tanto por atores públicos, quanto privados, e não apenas por aqueles cuja atividade tem fins lucrativos. Organizações sociais privadas de defesa de interesses públicos ou sociais igualmente passam a calcular a relação custo-benefício existente entre estratégias de persuasão social ampla e construção de consensos traduzíveis em novos direitos positivos, e aquele de persuasão judicial estrita em fóruns contramajoritários.

\section{e) Organizações e Instituições}

Da preocupação em constituir uma estrutura análoga à do Estado nacional resulta que na primeira fase de desenvolvimento da governança global ao longo do Século XX as organizações internacionais protagonistas, ao lado dos Estados nacionais, fossem a Liga das Nações, como espaço central de deliberações, e a Corte Permanente de Justiça Internacional, órgão de resolução de conflitos. Outras organizações existentes tinham reduzida importância.

No estilo de governo da segunda fase, para além dos Estados e das organizações centrais, especialmente a Assembleia Geral da Organização das Nações Unidas, o Conselho de Segurança, e a Corte Internacional de Justiça, inúmeras agências especializadas passam a ser centrais para o entendimento da governança global, tornando-se impossível pensar em uma explicação, por exemplo, sobre governança econômica, que não inclua o Fundo Monetário Internacional. Ainda, nesta fase, diversos mecanismos de governança transnacional (ou supranacional) são estabelecidos. A União Europeia e suas diversas organizações constituem o exemplo mais evidente.

$\mathrm{Na}$ terceira fase uma mudança de foco rumo às cortes ocorre com o fortalecimento e ganho de relevância daquelas já existentes, a instituição de inúmeros mecanismos judicias, permanentes e provisórios, para a solução de conflitos, e o estabelecimento de formas privadas de litígio. O Tribunal Penal Internacional e os tribunais ad hoc para a antiga Iugoslávia e para Ruanda exemplificam casos de judicialização pública de conflitos políticos abrangentes por meio de organizações internacionais. Os tribunais de arbitragem e mecanismos análogos constituem casos de ampliação dos espaços de adjudicação privada. Com a expansão de agências e as dissoluções de fronteiras estruturantes entre doméstico e internacional, público e privado, mais que complementarem umas às outras, as organizações de governo passam a muitas vezes competir por capacidade de regulação, cada qual estabelecendo mecanismos judiciais próprios em seu interior. Diferentes arranjos se conformam em resposta a esse fenômeno. 
No caso específico dos direitos fundamentais, espaços de governança regionais, supranacionais, transnacionais e internacionais passam a formular conceitos e conceber mecanismos de compatibilização de decisões (cf.: Torelly, 2016-A). Neste momento, o pluralismo legal se traduz em fragmentação de critérios decisórios e perspectivas sobre as formas de organização da relação não apenas entre regimes do Direito Internacional, mas entre esses e aqueles de governança nacional (as ordens jurídicas domésticas).

\section{f) Atores}

Na primeira fase de desenvolvimento da governança global esboçada, Estados nacionais e organizações internacionais constituíam a integralidade da ordem internacional. $\mathrm{Na}$ segunda fase, com os regimes especializados, inúmeras organizações de natureza temática ou transnacionais, públicas e privadas, passam a interagir de maneira permanente nos processos de governança. A terceira fase, por sua vez, abre a ordem internacional para um número potencialmente infinito de novos atores. Qualquer ator, público ou privado, individual ou coletivo, pode litigar e, por meio do litígio, legitima um espaço institucional de resolução de conflito e se legitima como agente. Em abordagens como a do processo jurídico transnacional de Harold Koh, todo o agente com capacidade fática de ação torna-se, potencialmente, um ator jurídico relevante.

Embora, evidentemente, distintas cortes apresentem distintos critérios de acesso, como tendência o elemento central a ser destacado é essa enorme abertura de possibilidades e, especialmente, o fato da articulação entre atores no espaço transnacional impactar inclusive os Estados nacionais. A ampliação e emergência de novos atores ilustra a mudança de um sistema eminentemente interestatal, no início do Século XX, para outro, altamente transversal, ao seu final. Como consequência, as categorias de legitimação tanto do direito doméstico, quanto do Direito Internacional, passam a ser questionadas. Perspectivas substantivas são gradualmente substituídas por outras, funcionais, em um processo em que projetos descritivos e normativos muitas vezes se confundem na formulação de categorias jurídicas.

\section{g) Abordagens Teóricas}

Um último elemento diferenciador a ser destacado são os tipos de abordagens teóricas preponderantes ao longo de cada período. A primeira fase caracterizou-se pela influência do positivismo jurídico, de uma ideia de engenharia social e do atrelamento entre legitimidade e estatalidade. A segunda, pela ideia de balanço de poder, realismo funcionalista, e de disputa na construção de uma ordem global. A terceira fase mantém a influência funcionalista, mas se caracteriza pelo pragmatismo, pelo atrelamento entre legitimidade e expertise, e pelo humanismo de matriz liberal implícito na ideia de um discurso técnico dos direitos fundamentais capaz de superar contextos políticos hostis.

O fim da Guerra Fria produziu grande entusiasmo quanto à possibilidade de substituição das abordagens de balanço de poder por outra, de governança por normas internacionais. Não obstante, as mudanças estruturais nos processos de governança conduziram a outro cenário: sem abandonar a ideia de uma governança baseada em regras, seu eixo de produção foi deslocado e fragmentado. Menos do que a então sonhada efetivação de um modelo mais coerente e unitário, o cenário em consolidação é outro, em que não mais Estados, mas regimes públicos e privados competem para se fazerem prevalecer como espaços hegemônicos.

\section{REFERÊNCIAS}


BERMAN, Nathaniel Berman. "Modernism, Nationalism, and the Rhetoric of Reconstruction". Yale Journal of Law and the Humanities, vol. 02, 1992, pp. 351-380.

CARDOSO, Evora Lusci Costa. Litígio Estratégico e Sistema Interamericano de Direitos Humanos. Coleção Fórum Direitos Humanos, vol.04. Belo Horizonte: Fórum, 2012.

ESTY, Daniel C. "Good Governance at the Supranational Scale: globalizing administrative law". The Yale Law Journal, vol.115, nº 07, 2006.

GRIMM, Dieter. "The Constitution in the Process of Denationalization". Constellations, vol.12, no $04,2005$.

HOLSTI, Kalevi J. Peace and War: Armed Conflicts and International Order 1648-1989. Cambridge: Cambridge University Press, 1991.

HOWSE, Robert; TEITEL, Ruti. "Beyond compliance: rethinking why International law really matters", Global Policy, Vol.01, n 02, 2010.

KALDOR, Mary. "Governance, Legitimacy, and Security: three scenarios for the Twenty First Century.” In: WAPNER, Paul; EDWIN Jr, Lester (org.). Principled World Politics: the challenge of normative international relations. Lanham: Rowman \& Littlefield, 2000.

KELSEN, Hans. Pure Theory of Law. Translation of the $2^{\text {nd }}$ Edition by Max Knight. Los Angeles/Berkeley: University of California Press, 1967.

KENNEDY, David Kennedy. "Receiving the International”. Connecticut Journal of International Law. Vol.10, 1994.

KENNEDY, David. "One, Two, Three, Many Legal Orders: Legal Pluralism and the Cosmopolitan Dream” NYU Review of Law and Social Change, vol.31, 2007.

KENNEDY, David. “The Move to Institutions”. Cardozo Law Review, v.08, 1987-b.

KENNEDY, David. "The Sources of International Law". American University Journal of International Law, vol.02, nº1, 1987-a.

KENNEDY, David. "Tom Franck and the Manhattan School”. NYU Journal of International Law and Politics, vol. 35, 2003.

KINGSBURY, Benedict; KRISCH, Nico; STEWART, Richard B. "The Emergence of Global Administrative Law". Law and Contemporary Problems, vol.68, n³/4, 2005.

KOH, Harold H. “Transnational Legal Process”. Nebraska Law Review, vol.75, 1996.

KOSKENNIEMI, Martii; LEINO, Päivi. "Fragmentation of International Law? Postmodern Anxieties". Leiden Journal of International Law, vol. 15, 2002. 
MORGENTHAU, Hans J. "Positivism, Functionalism, and International Law". The American Journal of International Law, Vol. 34, N. ${ }^{\circ}$ 02, 1940, pp. 260-284.

NEVES, Marcelo. Transconstitucionalismo. São Paulo: WMF Martins Fontes, 2009.

PATTBERG, Philipp. "The Institutionalization of Private Governance: How Business and Nonprofit Organizations Agree on Transnational Rules". Governance, vol.18, n 04, 2005, pp.589-610.

PREUSS, Ulrich. Disconnecting Constitutions from Statehood. In: DOBNER, Petra; LOUGHLIN, Martin. The Twilight of Constitutionalism? New York: Oxford University Press, 2010.

SASSEN, Saskia. Territory, Authority, Rights. Princeton: Princeton University Press, 2006.

SIMMA, Bruno; PULKOWSKI, Dirk. "Of Planets and the Universe: Self-contained Regimes in International Law”. European Journal of International Law, vol.17, nº 03, 2006.

SLAUGHTER, Anne-Marie. "A Global Community of Courts". Harvard International Law Journal, vol. 44, no. 01, 2003.

SLAUGHTER, Anne-Marie. "International law and international relations theory: a dual agenda", American Journal of International Law, vol.87, n02, 1993.

STARKE, J.G. "Monism and Dualism in the Theory of International Law," British Yearbook of International Law, n. ${ }^{\circ}$ 66, 1936.

TEITEL, Ruti. "Kosovo to Kadi: legality and legitimacy in contemporary International Order". Ethics and International Affairs, vol.28, $\mathrm{n}^{\circ}$ 01, 2014.

TEUBNER, Gunther. "Fragmented Foundations - societal constitutionalism beyond the Nation State," in: DOBNER, Petra; LOUGHLIN, Martin (orgs.), The Twilight of Constitutionalism. Oxford: Oxford University Press, 2010.

TEUBNER, Gunther. Constitutional Fragments: societal constitutionalism and globalization. New York: Oxford University Press, 2012.

TORELLY, Marcelo. "Unidade, Fragmentação e Novos Atores no Direito Mundial: leituras de operadores do Sistema Interamericano de Direitos Humanos sobre a formação de direitos globais no sistema regional". In: GALINDO, George Rodrigo Bandeira (org.). Fragmentação do Direito Internacional. Belo Horizonte: Arraes, 2015, pp.106-123.

TORELLY, Marcelo. Governança Transversal dos Direitos Fundamentais - experiências latinoamericanas. Tese de doutoramento apresentada à Faculdade de Direito da Universidade de Brasília, 2016-A, 300p. 
TORELLY, Marcelo. “Transnational Legal Process and Fundamental Rights in Latin America: How does the Inter-American Human Rights System Reshape Domestic Constitutional Rights?". In: FORTES, Pedro; BORATTI, Larissa, LLERAS, Andres Palacios; DALY, Tom Gerald. Law and Policy in Latin America: transforming courts, institutions, and rights. Londres: Palgrave Macmillan, 2016-B.

UNITED NATIONS. International Law Commission. Fragmentation of International Law: difficulties arrising from the diversification and expansion of International Law. (A/CN.4/L.682), Genebra, 2006. 